\section{Biological Monitoring of 4 Antineoplastic Drugs in Health Care Workers from 2 Adult Hospitals: A Pilot Study}

Up to 75000 Canadian workers are exposed to antineoplastic drugs, especially pharmacists, pharmacy technicians, and nurses. ${ }^{1}$ Adverse effects include risk of genotoxicity (evidenced by increases in genotoxicity biomarkers), reproductive risks (congenital malformations, miscarriages), and cancers. ${ }^{2,3}$ Canadian and US guidelines recommend environmental monitoring. ${ }^{4-7}$ Biological monitoring is mainly used in research settings, but could also help to confirm whether workers are free of contamination.

In a previous pilot project conducted in a mother-child hospital, ${ }^{8}$ no contamination was found in the urine of 101 workers tested. Although this finding was reassuring, it is recognized that results from a single centre may not be representative, especially given the lower doses prepared and the different drugs used for pediatric populations. We therefore sought to evaluate the feasibility of additional study and to explore potential differences for workers in adult care settings.

The study was conducted in 2 adult health care centres (750 beds [including 30 oncology beds] and 700 beds [including 28 oncology beds], respectively). Neither of the centres used closed-system drug transfer devices for compounding or administration of drugs. At one centre, all vials were washed upon receipt from the manufacturer; at the other centre, some vials were washed upon receipt. At one centre, IV tubing was primed in the pharmacy; at the other centre, IV tubing was primed by nurses on the various health care units.

The study protocol was approved by both institutional review boards in 2016. During the prestudy period, information sessions were presented (in January and June 2017, respectively) to describe the study and to increase workers' awareness and knowledge of the risks involved in working with antineoplastic drugs.

Workers who agreed to participate in the study provided informed consent. Each worker documented tasks performed and associated use of personal protective equipment by filling out a diary over a period of 5 days (the sampling day and the preceding 4 days). For each worker, 1 urine sample was collected in a $100-\mathrm{mL}$ polypropylene container at the end of the work shift. Samples were kept at $-20{ }^{\circ} \mathrm{C}$ and were later analyzed for cyclophosphamide (limit of detection $9.0 \mathrm{pg} / \mathrm{mL}$ ), ifosfamide (limit of detection $9.7 \mathrm{pg} / \mathrm{mL}$ ), methotrexate (limit of detection $75 \mathrm{pg} / \mathrm{mL}$ ), and $\alpha$-fluoro- $\beta$-alanine (FBAL, the main urinary metabolite of 5-fluorouracil; limit of detection $120 \mathrm{pg} / \mathrm{mL}$ ).
Drugs were quantified in positive electrospray multiple-reaction monitoring mode by ultra-performance liquid chromatography tandem mass spectrometer (Waters Xevo TQ-S system) by staff of the Centre de toxicologie du Québec. Pooled data are presented. The detailed method was published previously. ${ }^{8}$

Samples were collected in January and February 2017 at one centre and in June 2017 at the other centre. Twenty-eight workers were recruited at each centre, for a total of 56 participants (15 pharmacy technicians, 17 pharmacists, and 24 nurses). Most participants (54/56) had worked in hematology-oncology on the sampling day, and almost as many (49/56) had also worked in this setting on the previous day. Most participants were women (51/56), 41 participants were between 30 and 49 years of age, and overall the participants had worked a mean of 6.5 years (standard deviation 5.8 years) in oncology. Most of the nurses (23/24) had worked in the outpatient clinic on the sampling day, and 3 had also worked with inpatients. All of the pharmacists and pharmacy technicians worked in the oncology pharmacy. Half of the pharmacists (9/17) had visited inpatients on the day before sampling or on the sampling day.

The tasks related to antineoplastic drugs that were performed by participants are listed in Table 1 . One technician reported a slight spill on his gloves; no other incidents related to antineoplastic drugs were reported. None of the participants reported any difficulties or concerns regarding their participation in the study.

Most workers wore at least gloves for the majority of activities related to handling antineoplastic drugs (Table 2). The pharmacy technicians more often wore other personal protective equipment in addition to gloves. However, for some activities, such as storing vials, working in offices, transporting drugs, flushing the IV tubing, and other nontechnical activities, some workers wore no protection.

None of the 56 urine samples had any detectable concentrations of any of the 4 drugs.

This pilot project was successfully implemented in 2 adult health care centres. The results were similar to those previously obtained in a mother-child centre. ${ }^{8}$ No workers had detectable concentrations of antineoplastic drugs in their urine after their work shift. A wide variety of tasks were performed. Although gloves were frequently worn, many workers reported not wearing personal protective equipment. We suggest that whenever biological monitoring is conducted, it should be accompanied by information sessions for the workers, to remind them of safe handling practices and the use of protective equipment.

The absence of contamination in the urine of workers from these 2 adult centres can be explained by good handling practices, low surface contamination, the regular use of gloves, and the fact 


\section{Table 1. Potential Exposure to 4 Antineoplastic Drugs (Cyclophosphamide, Ifosfamide, Methotrexate, and 5-Fluorouracil)}

\begin{tabular}{|c|c|c|}
\hline Profession and Source of Exposure & Timing of Exposure & $\begin{array}{l}\text { Mean } \pm \text { SD } \\
\text { or Total No.* }\end{array}$ \\
\hline \multicolumn{3}{|l|}{ Pharmacy technicians $(n=15)$} \\
\hline $\begin{array}{l}\text { Time in oncology setting (hours) } \\
\text { (mean } \pm \text { SD) }\end{array}$ & $\begin{array}{l}\text { On sampling day } \\
\text { On day before sampling }\end{array}$ & $\begin{array}{l}7.0 \pm 1.7 \\
5.0 \pm 3.7\end{array}$ \\
\hline No. of vials handled & $\begin{array}{l}\text { On sampling day } \\
\text { On day before sampling }\end{array}$ & $\begin{array}{l}53 \\
33\end{array}$ \\
\hline No. of preparations compounded & $\begin{array}{l}\text { On sampling day } \\
\text { On day before sampling }\end{array}$ & $\begin{array}{l}30 \dagger \\
23\end{array}$ \\
\hline \multicolumn{3}{|l|}{ Pharmacists $(n=17)$} \\
\hline $\begin{array}{l}\text { Time in oncology setting (hours) } \\
\text { (mean } \pm \text { SD) }\end{array}$ & $\begin{array}{l}\text { On sampling day } \\
\text { On day before sampling }\end{array}$ & $\begin{array}{l}7.2 \pm 2.0 \\
7.0 \pm 2.6\end{array}$ \\
\hline No. of patients seen during rounds & $\begin{array}{l}\text { On sampling day } \\
\text { On day before sampling }\end{array}$ & $\begin{array}{l}10 \\
29\end{array}$ \\
\hline No. of preparations validated & $\begin{array}{l}\text { On sampling day } \\
\text { On day before sampling }\end{array}$ & $\begin{array}{l}57 \neq \\
81\end{array}$ \\
\hline No. of preparations packaged & On sampling day & $41 \neq$ \\
\hline \multicolumn{3}{|l|}{ Nurses $(n=24)$} \\
\hline $\begin{array}{l}\text { Time in oncology setting (hours) } \\
\text { (mean } \pm \text { SD) }\end{array}$ & $\begin{array}{l}\text { On sampling day } \\
\text { On day before sampling }\end{array}$ & $\begin{array}{l}7.1 \pm 2.2 \\
7.4 \pm 1.6\end{array}$ \\
\hline No. of IV tubing connections & $\begin{array}{l}\text { On sampling day } \\
\text { On day before sampling }\end{array}$ & $\begin{array}{l}45 \\
34\end{array}$ \\
\hline No. of IV tubing disconnections & $\begin{array}{l}\text { On sampling day } \\
\text { On day before sampling }\end{array}$ & $\begin{array}{l}25 \\
19\end{array}$ \\
\hline \multicolumn{3}{|c|}{$\begin{array}{l}\text { SD }=\text { standard deviation. } \\
\text { * Single values represent the total number for all personnel in each category. } \\
\text { +The } 30 \text { preparations entailed the following total amounts of drugs prepared on the sampling } \\
\text { day: ifosfamide } 0 \mathrm{mg} \text {, methotrexate } 555 \mathrm{mg} \text {, cyclophosphamide } 15050 \mathrm{mg} \text {, and 5-fluorouracil } \\
39685 \mathrm{mg} \text {. } \\
\text { †The } 57 \text { preparations validated and the } 41 \text { preparations packaged entailed the following } \\
\text { total amounts of drugs validated and packaged on the sampling day: ifosfamide } 2701 \mathrm{mg} \text {, } \\
\text { methotrexate } 536 \mathrm{mg} \text {, cyclophosphamide } 27640 \mathrm{mg} \text {, and 5-fluorouracil } 155385 \mathrm{mg} \text {. }\end{array}$} \\
\hline
\end{tabular}

that both centres have participated in environmental monitoring studies for many years, such that workers from these centres may have increased awareness of the risks associated with antineoplastic drugs.

Four drugs with differing half-lives (ranging from about 2 to about $10 \mathrm{~h}$ ) were used in the study centres and tested in this pilot study. It is not possible to identify a single point during a shift when a worker is exposed to antineoplastic drugs; rather, exposure to small amounts likely occurs throughout the day. Identifying a single sampling method that would be optimal for all drugs and all workers is potentially challenging. Spot urine sampling at the end of a shift was chosen previously to evaluate a convenient and cost-effective method that could become part of a national program. ${ }^{8}$ Similar results were obtained in 2 studies that implemented routine monitoring programs with spot urine sampling, one in Italian hospitals ( $0 \%$ positive samples) ${ }^{9}$ and one in French hospitals (4\% positive samples). ${ }^{10}$

Although spot sampling is less cumbersome and less costly, 24-h sampling covers a longer span of time and might increase the chances of finding contamination, if present. However, a longer sampling period might not be needed if the intention is to perform routine evaluation in a specified work setting. Both methods have been used previously by research groups from many countries, but the results have not been formally compared. Maeda and others ${ }^{11}$ found no positive urine samples with either 24-h sampling or spot sampling. In their recent study, Koller and others ${ }^{12}$ found no urine samples testing positive for cyclophosphamide or 5-fluorouracil with spot pre-shift and post-shift sampling for 5 consecutive days. Conversely, Sabatini and others ${ }^{13}$ found that up to $36 \%$ of workers had positive urine samples (with spot sampling). However, the rate of contamination declined to $0 \%$ over time, ${ }^{13}$ a finding similar to that of Sottani and others ${ }^{14}$ (who also used spot sampling). Using 24-h sampling, another Canadian group found that $55 \%$ of urine samples tested positive. $^{15}$ Thus, we cannot know with certainty whether the results of the current study would have been different if a different sampling method had been used.

No issues of concern were reported by pharmacy technicians, pharmacists, and nurses participating in this study, which is a good indication that a national monitoring program would be feasible. For this exploratory study, workers were briefed before their participation. We recruited centres that performed regular environmental monitoring and that expressed an interest in this topic, so the results may not be representative of all Canadian centres.

In conclusion, none of the workers evaluated in 2 Canadian adult health care centres had detectable concentrations of 
Table 2. Self-Reported Use of Personal Protective Equipment (PPE) When Performing Tasks with Antineoplastic Drugs

Type of PPE; No. (\%) of Tasks

\begin{tabular}{|c|c|c|c|c|c|c|}
\hline \multirow{2}{*}{$\begin{array}{l}\text { Profession and Task } \\
\text { Pharmacy technicians }\end{array}$} & \multicolumn{2}{|c|}{ Gloves + Other PPE } & \multicolumn{2}{|c|}{ Gloves Only } & \multicolumn{2}{|c|}{ No PPE } \\
\hline & & & & & & \\
\hline Receipt of drugs & $6 / 9$ & (67) & $1 / 9$ & (11) & 2/9 & $(22)$ \\
\hline Storage or drugs & $4 / 10$ & (40) & $4 / 10$ & (40) & $2 / 10$ & (20) \\
\hline Nonsterile compounding & $1 / 1$ & (100) & $0 / 1$ & $(0)$ & $0 / 1$ & $(0)$ \\
\hline Sterile compounding & 7/7 & (100) & $0 / 7$ & (0) & $0 / 7$ & (0) \\
\hline $\begin{array}{l}\text { Cleaning (vials, hoods, } \\
\text { surfaces, pass-through)* }\end{array}$ & $30 / 34$ & (88) & $3 / 34$ & (9) & $1 / 34$ & (3) \\
\hline Waste disposal* & $13 / 13$ & (100) & $0 / 13$ & (0) & $0 / 13$ & (0) \\
\hline \multicolumn{7}{|l|}{ Pharmacists } \\
\hline Working in office & $0 / 15$ & (0) & $4 / 15$ & (27) & $11 / 15$ & (73) \\
\hline $\begin{array}{l}\text { Working at the hood } \\
\text { workstation }\end{array}$ & $4 / 13$ & (31) & $5 / 13$ & (38) & $4 / 13$ & (31) \\
\hline Cleaning a surface & $1 / 2$ & (50) & $1 / 2$ & (50) & $0 / 2$ & $(0)$ \\
\hline Waste disposal* & $1 / 3$ & (33) & $2 / 3$ & $(67)$ & $0 / 3$ & $(0)$ \\
\hline \multicolumn{7}{|l|}{ Nurses } \\
\hline Transporting drug† & $3 / 22$ & (14) & $6 / 22$ & (27) & $12 / 22$ & (55) \\
\hline Connecting IV tubing & $9 / 23$ & (39) & $13 / 23$ & (57) & $1 / 23$ & $(4)$ \\
\hline Disconnecting IV tubing & $8 / 23$ & (35) & $13 / 23$ & (57) & $2 / 23$ & (9) \\
\hline Flushing IV tubing & $2 / 23$ & (9) & $7 / 23$ & (30) & $14 / 23$ & (61) \\
\hline Administering drug & $11 / 23$ & (48) & $11 / 23$ & (48) & $1 / 23$ & (4) \\
\hline Cleaning a surface & $1 / 20$ & (5) & $18 / 20$ & (90) & $1 / 20$ & (5) \\
\hline Waste disposal & $13 / 23$ & (57) & $8 / 23$ & (35) & $2 / 23$ & (9) \\
\hline Nontechnical activities* & $0 / 24$ & $(0)$ & $14 / 24$ & (58) & $10 / 24$ & $(42)$ \\
\hline
\end{tabular}

*Some tasks were pooled. For each task, the denominator represents the total number of times all of these tasks were performed by all workers who reported the tasks.

tOne nurse reported using only a protective gown.

4 antineoplastic drugs in their urine. This absence of detectable contamination in exposed workers contrasts with the findings of other researchers, who have reported such contamination, and is a good indication of the effectiveness of measures in place in the 2 study centres. Further research is needed to evaluate the need for biological monitoring and to optimize the method before routine monitoring is offered outside the research context. Future studies will focus on determining the optimal time of sampling and eventually establishing whether there is a threshold amount of contamination that can be tolerated. Workers need to be reminded of the importance of wearing all recommended protective equipment to reduce their risk of adverse health effects.

\section{References}

1. Hall AL, Demers PA, Astrakianakis G, Ge C, Peters CE. Estimating nationallevel exposure to antineoplastic agents in the workplace: CAREX Canada findings and future research needs. Ann Work Expo Health. 2017;61(6): 656-8.

2. Villarini M, Gianfredi V, Levorato S, Vannini S, Salvatori T, Moretti M. Occupational exposure to cytostatic/antineoplastic drugs and cytogenetic damage measured using the lymphocyte cytokinesis-block micronucleus assay: a systematic review of the literature and meta-analysis. Mutat Res. 2016;770(Pt A):35-45.

3. Connor TH, Lawson CC, Polovich M, McDiarmid MA. Reproductive health risks associated with occupational exposures to antineoplastic drugs in health care settings: a review of the evidence. J Occup Environ Med. 2014;56(9):901-10.
4. USP general chapter $<800>$ hazardous drugs - handling in healthcare settings. Rockville (MD): The United States Pharmacopeial Convention; 2018 [cited 2018 May 29]. Available from: www.usp.org/compounding/ general-chapter-hazardous-drugs-handling-healthcare

5. Prevention guide: safe handling of hazardous drugs. Montréal (QC): Association paritaire pour la santé et la sécurité du travail du secteur affaires sociales; 2008 [cited 2018 May 29]. Available from: www.asstsas.qc.ca/sites/default/ files/publications/documents/Guides_Broch_Depl/GP65A_hazardous_ drugs.pdf

6. Environmental monitoring. In: Compounding: guidelines for pharmacies. Ottawa (ON): Canadian Society of Hospital Pharmacists; 2014.

7. Norme 2014.02 - Préparation de produits stériles dangereux en pharmacie. Montréal (QC): Ordre des pharmaciens du Québec; 2014 [updated 2017; Oct; cited 2018 May 29]. Available from: www.opq.org/fr-CA/ publications/normes-de-pratique-et-lignes-directrices/

8. Poupeau C, Tanguay C, Plante C, Gagné S, Caron N, Bussières JF. Pilot study of biological monitoring of four antineoplastic drugs among Canadian healthcare workers. J Oncol Pharm Pract. 2017;23(5):323-32.

9. Turci R, Minoia C, Sottani C, Coghi R, Severi P, Castriotta C, et al. Occupational exposure to antineoplastic drugs in seven Italian hospitals: the effect of quality assurance and adherence to guidelines. J Oncol Pharm Pract. 2011;17(4):320-32.

10. Canal-Raffin M, Khennoufa K, Martinez B, Goujon Y, Folch C, Ducint D, et al. Highly sensitive LC-MS/MS methods for urinary biological monitoring of occupational exposure to cyclophosphamide, ifosfamide, and methotrexate antineoplastic drugs and routine application. J Chromatogr B Analyt Technol Biomed Life Sci. 2016;1039:109-17.

11. Maeda S, Miyawaki K, Matsumoto S, Oishi M, Miwa Y, Kurokawa N. Evaluation of environmental contaminations and occupational exposures involved in preparation of chemotherapeutic drugs. Yakugaku Zasshi. 2010; 130(6):903-10. 
12. Koller M, Böhlandt A, Haberl C, Nowak D, Schierl R. Environmental and biological monitoring on an oncology ward during a complete working week. Toxicol Lett. 2018;298:158-63.

13. Sabatini L, Barbieri A, Lodi V, Violante FS. Biological monitoring of occupational exposure to antineoplastic drugs in hospital settings. Med Lav. 2012;103(5):394-401.

14. Sottani C, Porro B, Comelli M, Imbriani M, Minoia C. An analysis to study trends in occupational exposure to antineoplastic drugs among health care workers. J Chromatogr B Analyt Technol Biomed Life Sci. 2010; 878(27):2593-605.

15. Hon CY, Teschke K, Shen H, Demers PA, Venners S. Antineoplastic drug contamination in the urine of Canadian healthcare workers. Int Arch Occup Environ Health. 2015;88(7):933-41.

\section{Laure Chauchat}

Department of Pharmacy and Pharmacy Practice Research Unit Centre hospitalier universitaire Sainte-Justine

DPharm candidate with Université de Lorraine

Nancy, France

\section{Cynthia Tanguay, BS, MSC}

Department of Pharmacy and Pharmacy Practice Research Unit Centre hospitalier universitaire Sainte-Justine

Montréal, Quebec
Roxane Therrien, BPharm, MSC

Department of Pharmacy

CISSS de Laval

Laval, Quebec

Annick Dufour, BPharm, MSC

Department of Pharmacy

CISSS de la Montérégie-Centre

Greenfield Park, Quebec

Sébastien Gagné, BSc

Centre de toxicologie du Québec

Institut national de santé publique du Québec

Québec, Quebec

Nicolas J Caron, PhD

Centre de toxicologie du Québec

Institut national de santé publique du Québec

Québec, Quebec

Jean-François Bussières, BPharm, MSc, MBA, FCSHP, FOPQ

Department of Pharmacy and Pharmacy Practice Research Unit Centre hospitalier universitaire Sainte-Justine

Faculty of Pharmacy

Université de Montréal

Montréal, Quebec

Competing interests: None declared.

Funding: None received. 